\title{
SUPERAÇÃO DA DORMÊNCIA EM SEMENTES DE PARICARANA (Bowdichia virgilioides Kunth.) ${ }^{1}$
}

\author{
OSCAR JOSÉ SMIDERLE², LUÍS AUGUSTO MELO SCHWENGBER ${ }^{3}$
}

\begin{abstract}
RESUMO - A dormência é fenômeno pelo qual sementes de uma determinada espécie, mesmo sendo viáveis e tendo as condições ambientais adequadas, não germinam. $\mathrm{O}$ estudo foi realizado objetivando avaliar efeitos da imersão das sementes por diferentes tempos em água em ebulição, sem ou com imersão posterior em hipoclorito de sódio para superação da dormência nas sementes de paricarana. As sementes foram previamente homogeneizadas e separadas por tamanho e cores, sendo utilizadas as sementes de coloração vermelha. Os tratamentos aplicados foram: $\mathrm{T} 1$ = imersão instantânea em água a $100{ }^{\circ} \mathrm{C}$ por 1 segundo; $\mathrm{T} 2=$ imersão em água a $100{ }^{\circ} \mathrm{C}$ por 10 segundos; $\mathrm{T} 3=\mathrm{T} 2+$ posterior imersão em hipoclorito de sódio $(2,5 \%)$ por 1 minuto; $\mathrm{T} 4=$ imersão em água a $100{ }^{\circ} \mathrm{C}$ por 20 segundos; T5 $=\mathrm{T} 4+$ posterior imersão em hipoclorito de sódio por 1 minuto. Foram utilizadas quatro repetições de 50 sementes em cada tratamento. Os maiores valores de germinação foram obtidos com a imersão das sementes em água aos $100{ }^{\circ} \mathrm{C}$ por 10 segundos, com ou sem posterior utilização do hipoclorito de sódio, sendo este procedimento recomendado para a superação da dormência tegumentar de sementes de paricarana (Bowdichia virgilioides). A imersão das sementes de paricana no hipoclorito de sódio por 1 minuto, após a imersão das sementes em água, entretanto, facilita a embebição e reduz a deterioração das sementes.
\end{abstract}

Termos para indexação: escarificação, emergência, embebição.

\author{
ALLEVIATION OF SEEDS DORMANCY IN THE \\ PARICARANA TREE (Bowdichia virgilioides Kunth.)
}

\begin{abstract}
Dormancy is a phenomenon in which seeds of a species do not germinate, even when they are viable and environmental conditions are suitable. The objective of this study was to assess the effects on seeds of different periods of immersion in boiling water, with or without posterior immersion in sodium hypochlorite, on the alleviation of paricarana (Bowdichia virgilioides Kunth.) seed dormancy. Seeds were previously homogenized and separated according to size and color, with red-colored seeds being used. The treatments applied were: $\mathrm{T} 1=$ immersion in water at $100{ }^{\circ} \mathrm{C}$ for one second; $\mathrm{T} 2=$ immersion in water at $100{ }^{\circ} \mathrm{C}$ for 10 seconds; $\mathrm{T} 3=\mathrm{T} 2$ + posterior immersion in $2.5 \%$ sodium hypochlorite for 1 minute; $\mathrm{T} 4=$ immersion in water at $100{ }^{\circ} \mathrm{C}$ for 20 seconds; T5 $=\mathrm{T} 4+$ immersion in $2.5 \%$ sodium hypochlorite for 1 minute. Each treatment consisted of four replicates of 50 seeds. The highest emergence scores were obtained with seed immersion in water at $100^{\circ} \mathrm{C}$ for 10 seconds, with or without the posterior use of sodium hypochlorite. This is the recommended procedure for breaking the seed tegument dormancy of paricarana (B. virgilioides). Immersion of paricarana seeds in sodium hypochlorite for one minute, after seed immersion in water, facilitates imbibition and reduces seed deterioration.
\end{abstract}

Index terms: scarification, emergence, imbibitions.

${ }^{1}$ Submetido em $12 / 02 / 2010$. Aceito para publicação em 15/01/2011.

${ }^{2}$ Eng.Agr. Dr. Pesquisador A, Embrapa Roraima, Caixa Postal 133,
69301-970. Boa Vista, RR. ojsmider@cpafrr.embrapa.br

${ }^{3}$ Eng. Agr., Universidade Federal de Roraima UFRR. CP 25007, CEP: 69304-000. Boa Vista, RR. 


\section{INTRODUÇÃO}

A Bowdichia virgilioides é espécie arbórea que pode atingir até 20 metros de altura, pertencente à família Fabaceae, com ampla distribuição pelo Brasil, ocorrendo com maior frequência nas regiões Norte, Nordeste e Centro-Oeste. É conhecida popularmente como paricarana, sucupira-preta e sucupira-do-cerrado (Lorenzi, 1992) sendo bastante utilizada no paisagismo, em programas de reflorestamento, na recuperação de áreas degradadas e em áreas de preservação permanente (Lorenzi, 1992). Seus frutos são legumes, indeiscentes, achatados, contendo pequenas sementes com 3 a $5 \mathrm{~mm}$ de comprimento, de coloração avermelhada. As suas sementes são abundantes em proteínas resistentes ao calor, mantendo-se presentes durante todo o processo germinativo (Albuquerque, 2006).

Em Roraima, a paricarana ocorre no tipo de savana denominada Baixo Surumú, onde predominam regiões de média e baixa altitude, árvores isoladas, presença de lagoas temporárias e igarapés (Silva, 1997). Nas áreas de cerrado em Roraima é comum verificar a delimitação de propriedades com cercas feitas de estacas de paricarana. Este uso pode estar associado com a reconhecida capacidade de resistência ao fogo, atribuída à paricarana, de ocorrência comum no cerrado durante o período de estiagem (Oliveira et al., 2008).

As sementes de paricarana apresentam dormência tegumentar, um tipo de dormência bastante comum em espécies da família das Fabaceae. Diversos métodos têm sido testados para romper a impermeabilidade do tegumento nessa espécie, podendo citar a escarificação química com ácido sulfúrico, a escarificação mecânica com lixa d'água, o uso de solventes com álcool etílico, a imersão em água a temperatura ambiente $\left(30^{\circ} \mathrm{C}\right)$ e a imersão em água quente (entre 80 e $100{ }^{\circ} \mathrm{C}$ ).

Embora seja um mecanismo eficiente para garantir a sobrevivência e perpetuação da espécie, a dormência se constitui num fator limitante à sua propagação, tendo em vista que apenas pequenas porcentagens das sementes germinam em condições naturais (Lopes et al., 1998). A impermeabilidade do tegumento à água consiste em um tipo de dormência que pode ser superado por meio da escarificação, termo que se refere a qualquer tratamento que resulte na ruptura ou no enfraquecimento do tegumento permitindo a passagem de água e dando início ao processo da germinação (Mayer e Poljakoff-Mayber, 1989).

De acordo com Eira et al. (1993), todos métodos apresentam vantagens e desvantagens, de modo que a metodologia de superação de dormência de sementes de uma espécie deve ser determinada levando-se em conta, também a praticidade e o custo efetivo.

O tratamento com água em ebulição $\left(100^{\circ} \mathrm{C}\right)$ é prático e econômico, sendo de fácil acesso e sem produção de resíduos tóxicos. $\mathrm{O}$ ácido sulfúrico necessita de cuidados no seu manuseio, é tóxico, de custo elevado e difícil aquisição sendo necessário recolher seu resíduo após o tratamento das sementes. O hipoclorito de sódio é uma sustância alcalina com capacidade oxidante, que captura o oxigênio, matando os microrganismos aeróbicos e os esporos dos fungos, que são, geralmente, os maiores responsáveis pelas contaminações das sementes (AlvarezPardo et al., 2006).

O hipoclorito de sódio é recomendado como teste para identificação de danos mecânicos em semente de soja, feijão e outras espécies da família das Fabaceae (Krzyzanowski et al. 2004). É muito utilizado em laboratórios de sementes para assepsia de sementes e propágulos vegetativos e em técnicas de micropropagação.

A utilização do hipoclorito de sódio é também recomendada na literatura na concentração de $0,5 \%$ para superação da dormência de algumas sementes, permitindo a entrada de gases e/ou água, no tempo de 24 horas (Brasil, 2009). A sua atuação ocorre, provavelmente, na degradação da lignina da parede de suas células (Sofiatti et al., 2008). São reações de oxidação, substituição ou adição de cloro no anel aromático presente na molécula de lignina (Hise, 1996). O hipoclorito de sódio possui capacidade de degradar ácidos graxos e lipídeos (Estrela et al., 2002).

Andrade et al. (1997), buscando selecionar os tratamentos pré-germinativos em laboratório, que permitissem abreviar, aumentar e uniformizar a germinação de sementes de $B$. virgilioides, visando otimizar o monitoramento de sua viabilidade em bancos de germoplasma, testaram diversos tratamentos, como: imersão em ácido sulfúrico concentrado (98\%) por 1, 5,10 e 20 minutos; imersão em água em ebulição (100 $\left.{ }^{\circ} \mathrm{C}\right)$ por 1,2 e 3 minutos; imersão em água em $30{ }^{\circ} \mathrm{C}$ por 24 horas e controle (sem tratamento). De acordo com os autores, os tratamentos mais eficientes foram a imersão em ácido sulfúrico por 5 e 10 minutos.

Gonçalves et al. (2008), em um estudo objetivando avaliar o efeito da pré-embebição na germinação de sementes de $B$. virgilioides que haviam sido escarificadas com ácido sulfúrico $\left(\mathrm{H}_{2} \mathrm{SO}_{4}\right)$ por 5 minutos, concluíram 
que os tempos de 36 e 48 horas em água à $30{ }^{\circ} \mathrm{C}$ apresentaram os melhores resultados. Sampaio et al. (2001), observaram que a imersão de sementes de $B$. virgilioides por um período de 8 a 11 minutos em $\mathrm{H}_{2} \mathrm{SO}_{4}$ concentrado (95 - 98\%) proporcionou germinação de $70 \%$ e $80 \%$, respectivamente. Já Smiderle e Sousa (2003), avaliando o efeito de diferentes métodos de escarificação também na superação da dormência em sementes de $B$. virgilioides, observaram que a imersão em $\mathrm{H}_{2} \mathrm{SO}_{4}$ por 5 minutos e a escarificação mecânica com lixa d'água por 1 minuto foram os mais eficientes, com germinação de 90 e $79 \%$ aos 30 dias, respectivamente.

Como visto, diversos autores conseguiram superar a dormência em sementes de $B$. virgilioides Kunth., porém com a utilização de ácido sulfúrico ou lixa d'água. Dessa forma, este trabalho objetivou a avaliação da eficiência do uso de água em ebulição em diferentes tempos, com e sem o uso de hipoclorito de sódio na superação da dormência tegumentar em sementes de Bowdichia virgilioides Kunth.

\section{MATERIAL E MÉTODOS}

O experimento foi conduzido nos meses de abril e maio de 2009, no Laboratório de Análise de Semente (LAS) da Embrapa Roraima, localizado no município de Boa Vista. As sementes utilizadas no estudo foram colhidas em 2007, na vila do Taiano - RR e mantidas armazenadas no LAS, em recipiente de vidro, em temperatura ambiente. Para sua utilização, as sementes foram previamente separadas em duas cores, vermelhas e pretas, por diferenças visuais, sendo utilizadas as de coloração vermelha. O grau de umidade foi determinado utilizando duas repetições de um grama de sementes, por meio do método da estufa a $105 \pm 3{ }^{\circ} \mathrm{C}$, por um período de 24 horas (Brasil, 2009).

Os tratamentos utilizados para superação de dormência foram: T1 = imersão instantânea em $100{ }^{\circ} \mathrm{C}$ por 1 segundo; $\mathrm{T} 2$ = imersão em água a $100{ }^{\circ} \mathrm{C}$ por 10 segundos; T3 = imersão em água a $100^{\circ} \mathrm{C}$ por 10 segundos e posterior imersão em solução de hipoclorito de sódio $(2,5 \%)$ por 1 minuto; $\mathrm{T} 4=$ imersão em água a $100{ }^{\circ} \mathrm{C}$ por 20 segundos; T5 = imersão em água a $100{ }^{\circ} \mathrm{C}$ por 20 segundos e, posteriormente, em solução de hipoclorito de sódio por 1 minuto.

Para realizar o teste de germinação, as sementes foram colocadas no interior de caixas 'gerbox', contendo papel 'germitest' umedecido com água na proporção de 2,5 vezes o seu peso. Foram utilizadas quatro repetições de 50 sementes em cada tratamento mantidas em ambiente a temperatura de $25{ }^{\circ} \mathrm{C}$. As contagens das sementes embebidas e deterioradas foram realizadas diariamente durante 22 dias, com reposição de água para manutenção da umidade quando necessária. A avaliação de sementes embebidas foi realizada de forma visual, constatada pelo escurecimento e aumento do volume das sementes (intumescimento). Foram consideradas emergidas aquelas sementes que apresentavam a protrusão radicular com comprimento maior que $2 \mathrm{~mm}$. As sementes germinadas e as deterioradas eram contadas diariamente e retiradas as que estavam deterioradas.

$\mathrm{Na}$ última avaliação (aos 22 dias) foram contadas as sementes embebidas, germinadas, deterioradas e as sementes duras remanescentes. Como germinadas considerou-se a percentagem de plântulas normais obtidas. Sementes deterioradas foram consideradas as que, além do desenvolvimento de estruturas fúngicas em seu entorno, ao serem tocadas com pinça liberavam liquido indicando estarem mortas. Sementes duras foram consideradas aquelas que não embeberam.

O índice de velocidade de emergência (IVE) foi calculado de acordo com a fórmula de Maguire (1962), em que: $\mathrm{IVE}=\mathrm{E} 1 / \mathrm{N} 1+\mathrm{E} 2 / \mathrm{N} 2+\ldots, \mathrm{En} / \mathrm{Nn}$. Onde: E1, E2, ..., En = número de sementes germinadas até o enésimo dia; N1, N2, ..., Nn = número de dias da instalação (semeadura) do experimento. Quanto aos índices de velocidade de embebição (IVEm) e de deterioração (IVD) foram calculados desta mesma forma.

O delineamento utilizado foi o inteiramente casualizado (DIC). Os dados obtidos em porcentagem de germinação foram submetidos a transformação arco seno $\sqrt{ }(\mathrm{x} / 100)$ para fins de análise estatística (Banzatto; Kronka, 1995). Os dados foram submetidos à análise de variância, pelo teste $\mathrm{F}$, e os valores médios foram comparados pelo teste de Tukey $(\alpha=5 \%)$, utilizando-se o Software SAEG (Ribeiro Júnior, 2001).

\section{RESULTADOS E DISCUSSÃO}

O grau de umidade (teor médio de água) determinado nas sementes de paricarana utilizadas para a instalação do experimento foi de $8,6 \%$. Esse dado corrobora com os valores da umidade das sementes de paricarana auferidos por Albuquerque (2006) e Andrade et al. (1997), que trabalharam com graus de umidade de $9 \%$ e $8,7 \%$, respectivamente.

Os tratamentos T3, T4 e T5 resultaram em 100\% 
de sementes de $B$. virgilioides embebidas aos 22 dias, enquanto nos tratamentos T2 e T1 verificou-se $99,5 \%$ e $54,5 \%$, respectivamente. Os valores de embebição das sementes no tratamento T1 foram significativamente $(\alpha$ $=5 \%$ ) inferiores aos obtidos para os demais, que não diferiram entre si (Tabela 1).

TABELA 1. Valores médios de sementes embebidas (EMB, \%), índice de velocidade de embebição (IVEm), porcentagem de germinação (GER), índice velocidade de emergência (IVE), sementes deterioradas (DETER, \%), índice de deterioração (IVD), sementes duras (DURAS, \%) obtidos em sementes de paricarana submetidas a diferentes tempos em água em ebulição, com e sem hipoclorito de sódio.

\begin{tabular}{ccclcccc}
\hline Tratamento & EMB $(\%)$ & IVEm & GER $(\%)$ & IVE & DETER (\%) & IVD & DURAS (\%) \\
\hline T1 & $54,5 \mathrm{~b}$ & $2,4 \mathrm{~d}$ & $26 \mathrm{~d}$ & $1,4 \mathrm{~d}$ & $1,5 \mathrm{~d}$ & $0,1 \mathrm{c}$ & $44 \mathrm{a}$ \\
T2 & $99,5 \mathrm{a}$ & $10,4 \mathrm{c}$ & $81 \mathrm{ab}$ & $4,8 \mathrm{~b}$ & $12 \mathrm{bc}$ & $1 \mathrm{bc}$ & $1 \mathrm{~b}$ \\
T3 & $100 \mathrm{a}$ & $20,4 \mathrm{a}$ & $87 \mathrm{a}$ & $6,7 \mathrm{a}$ & $10 \mathrm{~cd}$ & $0,9 \mathrm{bc}$ & $0 \mathrm{~b}$ \\
T4 & $100 \mathrm{a}$ & $17,4 \mathrm{~b}$ & $39 \mathrm{c}$ & $2,4 \mathrm{c}$ & $54 \mathrm{a}$ & $4,4 \mathrm{a}$ & $0 \mathrm{~b}$ \\
T5 & $100 \mathrm{a}$ & $22,7 \mathrm{a}$ & $71 \mathrm{~b}$ & $4,4 \mathrm{~b}$ & $21,5 \mathrm{~b}$ & $1,7 \mathrm{~b}$ & $0 \mathrm{~b}$ \\
\hline C.V. & 1,8 & 7,6 & 9,7 & 8,4 & 23,5 & 23,5 & 67 \\
\hline
\end{tabular}

Médias seguidas pela mesma letra, na coluna, não diferem entre si, pelo teste de Tukey $(\mathrm{p}<0,05)$.

Onde: $\mathrm{T} 1$ = imersão instantânea em $100{ }^{\circ} \mathrm{C}$ por 1 segundo; $\mathrm{T} 2=$ imersão em água aos $100{ }^{\circ} \mathrm{C}$ por 10 segundos; $\mathrm{T} 3=\mathrm{T} 2+$ posterior imersão em hipoclorito de sódio $(2,5 \%)$ por 1 minuto; $\mathrm{T} 4=$ imersão em água aos $100{ }^{\circ} \mathrm{C}$ por 20 segundos; $\mathrm{T} 5=\mathrm{T} 4+$ posterior imersão em hipoclorito de sódio $(2,5 \%)$ por 1 minuto.

As sementes do T5 estavam embebidas a partir do quarto dia, as do T3 aos sete dias, e o T4 aos nove dias. Smiderle e Sousa (2003) obtiveram $100 \%$ das sementes de $B$. virgilioides embebidas aos dois e 16 dias quando as mesmas foram escarificadas em ácido sulfúrico $(98 \%)$ por 10 minutos e 5 minutos, respectivamente. Estes resultados indicam que a utilização de água em ebulição $\left(100^{\circ} \mathrm{C}\right)$ possibilitou a antecipação da embebição das sementes em relação ao obtido com $\mathrm{H}_{2} \mathrm{SO}_{4}$ por 5 minutos. No entanto a embebição das sementes é um processo físico ligado às propriedades das substâncias coloidais, ocorrendo tanto em sementes vivas, quanto em sementes mortas (Carvalho; Nakagawa, 2000).

A embebição é condicionada pela temperatura, sendo que as temperaturas mais elevadas ocasionam a uma maior embebição. De acordo com Mayer e PoljakoffMayber (1989), este fenômeno, provavelmente, está ligado às modificações da viscosidade e da energia cinética da água com o aumento da temperatura.

As sementes dos tratamentos T5 e T3 apresentaram as maiores médias de velocidade de embebição (índices de 22,7 e 20,4, respectivamente). Os índices de velocidade são importantes para avaliar a distribuição dos processos da germinação no tempo, no caso a embebição, dando uma relação entre o tempo e a uniformidade do processo. Dessa forma, não basta o T4 ter $100 \%$ de sementes embebidas aos 22 dias, é preciso analisar como essa embebição ocorreu no período.

Comparando-se o tratamento T2 com o T3, percebese que houve diferença significativa (Tabela 1), mostrando que, no tempo de imersão de 10 segundos, houve influência positiva da imersão das sementes em hipoclorito de sódio. Da mesma forma, houve diferença significativa entre o T4 e T5, ressaltando que houve efeito benéfico do hipoclorito. Dessa forma, pode-se inferir que a imersão das sementes de $B$. virgilioides em hipoclorito de sódio $(2,5 \%)$ por 1 minuto, após terem sido imersas em água a $100^{\circ} \mathrm{C}$ por 10 ou 20 segundos proporcionou aumento da velocidade de embebição em comparação a não utilização.

Comparando-se os tratamentos que registraram diferenças significativas no tocante ao tempo de imersão da água em ebulição, mas não foram imersos em hipoclorito de sódio, verifica-se que houve diferença no índice de velocidade de embebição (IVEm), sendo que o maior índice de velocidade de embebição é obtido na imersão das sementes em água a $100{ }^{\circ} \mathrm{C}$ por 20 segundos (T4), superando o tratamento de 10 segundos de imersão (T2), que por sua vez superou o tratamento de imersão 
instantâneo da água em ebulição (T1). Estes resultados permitem inferir que os maiores tempos de imersão em água em ebulição proporcionaram os maiores valores médios de IVEm nas sementes. Já os tratamentos de imersão, em água em ebulição, por 10 segundos (T3) e 20 segundos (T5), com posterior imersão em $\mathrm{NaClO}$ por 1 minuto, não diferiram significativamente no IVEm, embora o tempo de imersão na água a $100{ }^{\circ} \mathrm{C}$ tenha sido diferente.

Os tratamentos $\mathrm{T} 3$ e $\mathrm{T} 2$ resultaram nos maiores números de sementes germinadas aos 22 dias, com $87 \%$ e $81 \%$, respectivamente. O T2 não diferiu significativamente do $\mathrm{T} 5$, que teve $71 \%$ de sementes germinadas. O tratamento de imersão em água em ebulição por 10 segundos e posterior imersão em hipoclorito de sódio por 1 minuto (T3) não diferiu significativamente $(\alpha=5 \%)$, do tratamento de imersão em água em ebulição por 10 segundos (T2). Dessa forma, o hipoclorito de sódio $(2,5 \%)$ por 1 minuto não diferiu da não utilização no tempo de imersão de 10 segundos em água em ebulição, na germinação aos 22 dias. O T5, em comparação com o T4, apresentou diferença significativa entre as sementes, demonstrando que para o tempo de imersão de 20 segundos, a imersão em hipoclorito foi positiva.

Em relação aos diferentes tempos de imersão em água a $100{ }^{\circ} \mathrm{C}$, sem a imersão posterior em $\mathrm{NaClO}$, verifica-se que a imersão por 10 segundos (T2) resultou no melhor valor médio de germinação aos 22 dias, em comparação aos tempos de 20 segundos (T4) e de imersão instantânea por 1 segundo (T1), com valores médios de $39 \%$ e $26 \%$, respectivamente.

Andrade et al. (1997) observaram que a imersão de sementes de $B$. virgilioides em água em ebulição $\left(100^{\circ} \mathrm{C}\right)$ por 1,2 e 3 minutos, produziu os maiores valores médios de sementes embebidas, porém produziu os menores valores de germinação. Tal fato permite supor que a água em ebulição poderia apresentar melhores resultados com o uso de menores tempos de imersão. Já Albuquerque (2006), obteve 59 e $63 \%$ de sementes de B. virgilioides germinadas, aos 30 dias, utilizando para superação da dormência a imersão em água quente $\left(80^{\circ} \mathrm{C}\right)$ por 5 e 10 minutos, respectivamente.

Gonçalves et al. (2008) obtiveram germinação de até $82 \%$ em sementes de $B$. virgilioides, escarificadas em $\mathrm{H}_{2} \mathrm{SO}_{4}$ por cinco minutos conforme Smiderle e Sousa (2003) e posteriormente imersas em água à $30^{\circ} \mathrm{C}$ por 48 horas. Já Sampaio et al. (2001) atingiram germinação de $80 \%$ em sementes de sucupira preta. Smiderle e Sousa
(2003) obtiveram germinação de até $90 \%$ comparando métodos de superação de dormência das sementes de $B$. virgilioides. Portanto, a germinação de $87 \%$ obtida nesse trabalho, assemelha-se ao constatado na literatura, sendo que o método utilizado foi, para a maioria, escarificação química com $\mathrm{H}_{2} \mathrm{SO}_{4}$. Desta forma, estes resultados agora obtidos, com a utilização de água aquecida acrescida de hipoclorito para a obtenção de germinação de sementes da paricarana são importantes para redução de resíduos químicos gerados em laboratórios de sementes.

Maior índice de velocidade de emergência $(\mathrm{IVE}=6,72)$ foi observado para o $\mathrm{T} 3$ diferindo significativamente $(\alpha=5 \%)$ dos demais tratamentos (Tabela 1). Dessa forma, além de apresentar um dos maiores IVEm, este tratamento também resultou nas sementes de maior IVE, diferindo dos demais, demonstrando dessa forma que quando as sementes foram imersas em água a $100{ }^{\circ} \mathrm{C}$ por 10 segundos acrescido de 1 minuto em $\mathrm{NaClO}$ produziram maior percentual de germinação. Entre o T3 e o T2 houve diferença significativa, onde a utilização de $\mathrm{NaClO}$ acelerou o processo germinativo. As sementes do T3 apresentaram maior emergência entre o $12^{\circ}$ dia e o $16^{\circ}$ dia (Figura 1). Já para as sementes do T2 o maior acréscimo na emergência foi entre o $15^{\circ}$ dia e o $22^{\circ}$ dia.

A utilização de hipoclorito de sódio também foi positiva no tempo de 20 segundos em água a $100^{\circ} \mathrm{C}$ para o IVE, comparada a ausência do hipoclorito. O fator que pode explicar esse aumento na velocidade de emergência é, justamente, a maior velocidade de embebição auferida nos tratamentos que foram imersos em hipoclorito. A embebição é a primeira etapa do processo germinativo, e quanto mais cedo começa, existe tendência das etapas seguintes também serem influenciadas.

De forma semelhante ao verificado nos valores médios de germinação, quando foram comparados os tratamentos que não receberam hipoclorito, o tratamento de imersão em água à $100{ }^{\circ} \mathrm{C}$ por 10 segundos (T2) resultou no maior IVE, diferindo dos tratamentos de 20 segundos (T4) e 1 segundo (T1).

As sequências crescentes de valores, com o tempo, verificadas na figura 1 indicam as tendências para a emergência das sementes (protrusão da raiz) e posterior obtenção das plântulas normais para os cinco tratamentos aplicados às sementes de paricarana. Visualiza-se assim que já aos 16 dias, o tratamento 3 (T3), obteve o valor máximo, enquanto os outros dois melhores tratamentos (T2 e T4) até o vigésimo segundo dia ainda apresentavam acréscimos. 


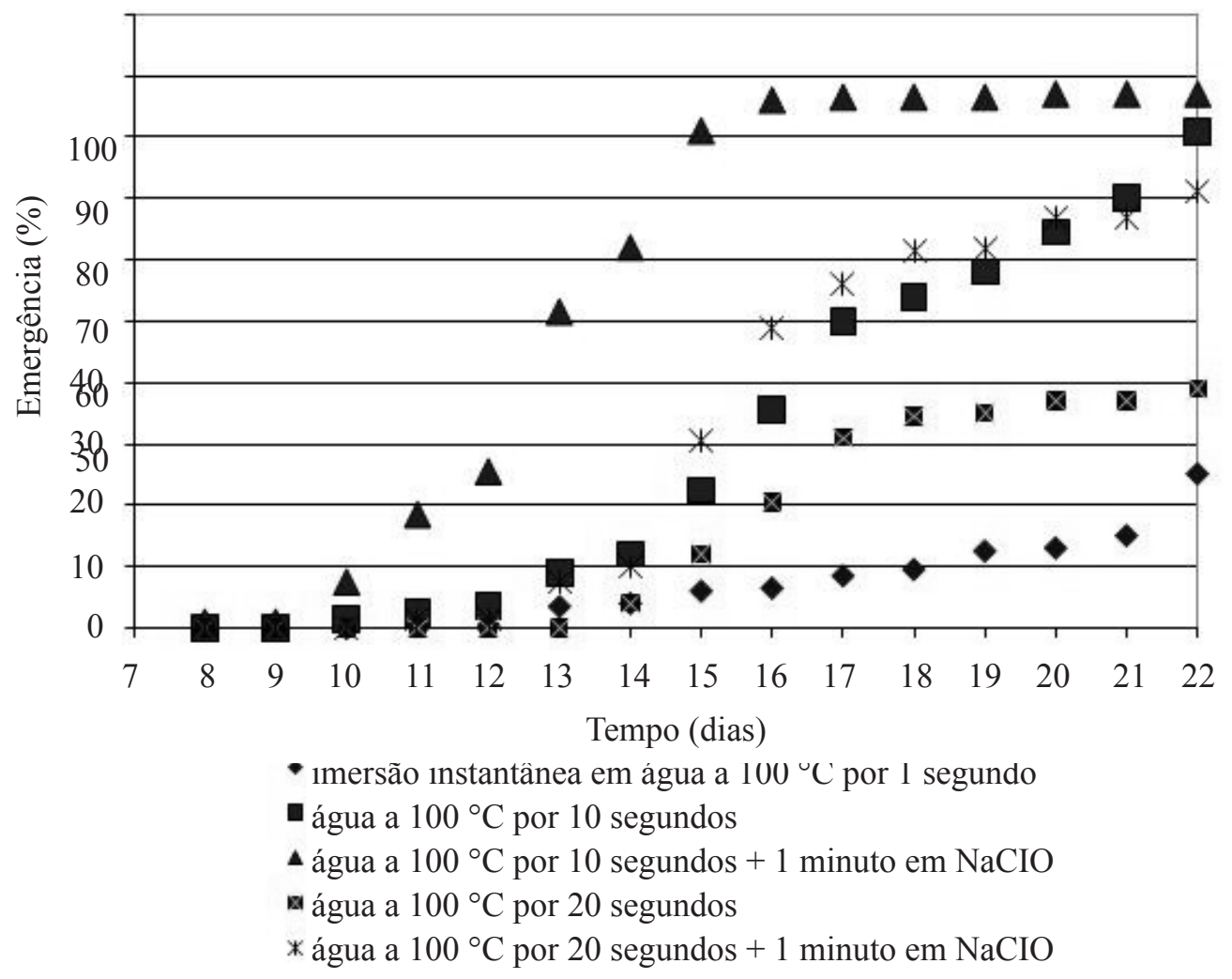

FIGURA 1. Valores acumulados de emergência em sementes de Bowdichia virgilioides obtidas em 22 dias, prétratadas em diferentes tratamentos de água em ebulição $\left(100{ }^{\circ} \mathrm{C}\right)$, com e sem hipoclorito de sódio.

Houve uma tendência dos maiores valores médios de germinação estarem associados aos maiores índices de velocidade de embebição. Albuquerque (2006) relata que este comportamento indica a existência de uma relação direta entre os dois processos, tendo sido observados também por Andrade et al. (1997) e Sampaio et al. (2001).

Em relação à deterioração (Tabela 1), as sementes oriundas dos tratamentos $\mathrm{T} 1 \mathrm{e}$ T3 apresentaram as menores taxas com $1,5 \%$ e $10 \%$ de sementes deterioradas aos 22 dias, seguidas pelas sementes do tratamento 3 (T3) que não diferiu significativamente do T2 (12\%). Enquanto o tratamento T4 apresentou o maior percentual de sementes deterioradas (54\%). Analisando-se os tratamentos T4 e $\mathrm{T} 5$, verifica-se grande diferença nos valores, de modo que a utilização do $\mathrm{NaClO}(2,5 \%)$ no T5 teve efeito benéfico, inclusive só aparecendo fungos sobre as sementes aos
18 dias após o início do experimento. No T4 estruturas fúngicas foram constatadas já aos 12 dias.

O uso de hipoclorito de sódio como agente desinfetante é bastante conhecido, sendo para este fim a sua principal utilização. Porém, levando-se em consideração os tratamentos T3 e T2 verifica-se que a utilização de $\mathrm{NaClO}$ não influenciou na deterioração das sementes no tempo de 10 segundos em água em ebulição. Nos demais tratamentos não foi evidenciado o aparecimento de fungos. Esses dados corroboram com Andrade et al. (1997), ao observarem que os tratamentos de imersão das sementes em água (ebulição por 1 e 2 minutos), e imersão em ácido sulfúrico por 15 e 20 minutos, apresentaram os maiores percentuais de anormalidades no teste de germinação. Além disso, a maioria das sementes não germinadas apresentavam-se intumescidas e recobertas por fungos depois de sete dias do início do experimento. 
Albuquerque (2006), submergindo sementes de $B$. virgilioides em água quente a $80^{\circ} \mathrm{C}$ por 5 e 10 minutos, obteve um excessivo número médio de sementes deterioradas (15 e $20 \%$ ), respectivamente, sendo que para o tempo de 10 minutos foi acima dos outros métodos testados. A autora relata que a alta temperatura empregada tenha, provavelmente, afetado a viabilidade do embrião, causando a deterioração. Pelo que foi verificado neste trabalho, não é a alta temperatura da água que danifica as sementes, mas sim o tempo em que as sementes permanecem em imersão na água aquecida.

No tocante às sementes duras, observou-se que restaram $44 \%$ de sementes duras aos 22 dias no tratamento $\mathrm{T} 1$, evidenciando que as sementes utilizadas apresentavam dormência tegumentar que impedia a entrada da água na semente. Já aquelas oriundas do tratamento T2 apresentaram $1 \%$ de sementes duras aos 22 dias, enquanto nos demais tratamentos não se constatou a presença de sementes duras (Tabela 1).

A imersão das sementes em água a $100{ }^{\circ} \mathrm{C}$ por 10 segundos, seguida da imersão em solução de hipoclorito de sódio $(2,5 \%)$ por 1 minuto (T3) foi o tratamento com maior destaque nos parâmetros analisados. De forma análoga, a imersão em água a $100{ }^{\circ} \mathrm{C}$ por 10 segundos (T2) também se apresentou como um procedimento satisfatório para superação da dormência de sementes de B. virgilioides, com germinação de $81 \%$. Porém, as sementes procedentes do T3 apresentaram maior uniformidade de embebição e emergência, constatado pelos maiores valores de IVEm e IVE. Esta uniformidade de emergência é uma característica muito importante para o viveirista, diminuindo o trabalho com o transplantio das plântulas, e possibilitando a produção de maior número de mudas mais uniformes e em menor tempo.

\section{CONCLUSÕES}

A imersão das sementes em água a $100{ }^{\circ} \mathrm{C}$ por 10 segundos, com ou sem posterior utilização do hipoclorito de sódio, é um procedimento recomendado para a superação da dormência tegumentar de sementes de paricarana (Bowdichia virgilioides).

A imersão das sementes de paricana no hipoclorito de sódio por 1 minuto, após a imersão das sementes em água, facilita a embebição e reduz a deterioração das sementes.

\section{REFERÊNCIAS}

\section{ALBUQUERQUE, K.S. Aspectos fisiológicos da}

germinação de sementes de sucupira-preta (Bowdichia virgilioides Kunth.). 2006. 90f. Dissertação (Mestrado em Agronomia)- Universidade Federal de Lavras, Lavras, 2006.

ALVAREZ-PARDO, V.M.; FERREIRA, A.G.; NUNES, V.F. Seed disinfestation methods for in vitro cultivation of epiphyte orchids from Southern Brazil. Horticultura Brasileira, v.24, n.2, p.217-220, 2006.

ANDRADE, A.C.S.; LOUREIRO, B.M.; SOUZA, A.D. de O.; RAMOS, F.N. Quebra de dormência de sementes de sucupira-preta. Pesquisa Agropecuária Brasileira, v.32, n.5, p.465-469, 1997.

BANZATTO, D.A.; KRONKA, S.N. Experimentação agrícola. 3.ed. Jaboticabal: FUNEP, 1995. 247 p.

BRASIL. Ministério da Agricultura, Pecuária e Abastecimento. Regras para análises de sementes. Ministério da Agricultura, Pecuária e Abastecimento. Secretaria de Defesa Agropecuária. Brasília, DF: Mapa/ ACS, 2009. 399p.

CARVALHO, N.M., NAKAGAWA, J. Sementes: ciência, tecnologia e produção. Jaboticabal: FUNEP, 2000. 588p.

EIRA, M.R.S.; FREITAS, R.W.A.; MELLO, C.M.C. Superação da dormência de sementes de Enterlobium contortisiliquum (VELL.) Morong. - Leguminosae. Revista Brasileira de Sementes, v.15, p.177-182, 1993.

ESTRELA，C.; ESTRELA，C.R.A.; BARBIN， E.L.; SPANÓ, J.C.E.; MARCHESAN, M.A.; PÉRCORA, J.D. Mechanism of action of sodium hypochlorite. Brazilian Dental Journal, v.13, n.2, p.113-117, 2002.

GONÇALVES, J.V.S.; ALBRECHT, J.M.F.; SOARES, T.S.; TITON, M. Caracterização física e avaliação da pré-embebição na germinação de sementes de sucupirapreta (Bowdichia virgilioides KUNTH.). Cerne, v.14, n.4, p.330-334, 2008.

HISE, R. Chlorination. IN: DENCE, C.W.; REEVE, D.W. Pulp bleaching - principles and practice. Atlanta, Georgia - USA: Tappi Press, 1996. Seção IV, cap. 2, p. 241-259.

KRZYZANOWSKY, F.; FRANÇA, J.B.; COSTA, N.P. Teste de hipoclorito de sódio para sementes de soja. Londrina: Embrapa Soja, 2004. 4p.(Circular Técnica 37).

LOPES, J.C.; CAPUCHO, M.T.; KROHLING, B.; ZANOTTI, P. Germinação de sementes de espécies florestais de Caesalpinea ferrea Mart. Ex Tul. Var. leiostachya Benth., Cassia grandis L. e Samanea saman Merrill, após tratamento para superar a dormência. Revista 
Brasileira de Sementes, v.20, n.1, p.80-86, 1998.

LORENZI, H. Árvores brasileiras. São Paulo: Plantarum, 1992. 368p.

MAGUIRE, J.D. Speed of germination aid in selection and evaluation for seedling emergence and vigor. Crop Science, v.2, n.2, p.176-177, 1962.

MAYER, A.M.; POLJAKOFF-MAYBER, A. The germination of seeds. Oxford: Pergamon Press, 1989. $270 \mathrm{p}$.

OLIVEIRA, J.M.F. de.; SCHWENGBER, D.R.; SMIDERLE, O.J. Ocorrência da Paricarana (Bowdichia virgilioides) em Três Municípios de Roraima e sua Relação com as Características do Solo. Boa Vista: Embrapa Roraima. 2008 (Embrapa Roraima. Comunicado Técnico, 21).

RIBEIRO JÚNIOR, J.I. Análises estatística no SAEG. Viçosa: Universidade Federal de Viçosa, 2001, 301p.
SILVA, E.L.S. A vegetação de Roraima. In: BARBOSA, R.I.; FERREIRA, E.J.G.; CASTELLÓN, E.G. (Ed.). Homem, ambiente e ecologia no Estado de Roraima. Manaus: Inpa, 1997. p.401-415.

SMIDERLE, O.J.; SOUSA R. de C.P. Dormência em sementes de paricarana (Bowdichia virgiliodes KunthFabaceae - Papilionidae). Revista Brasileira de Sementes, v. 25, n.2, p.48-52, 2003.

SAMPAIO, L.S. de V.; PEIXOTO, C.P.; PEIXOTO, M. de F. da S.P.; COSTA, J.A.; GARRIDO, M. da S.; MENDES, L.N. Ácido sulfúrico na superação da dormência de sementes de sucupira preta (Bowdichia virgilioides Kunth. - Fabaceae). Revista Brasileira de Sementes, v.23, n.1, p.184-190, 2001.

SOFIATTI, V.; ARAUJO, E.F.; ARAUJO, R.F.; REIS, M.S.; SILVA, L.V.B.D.; CARGNIN, A. Uso de hipoclorito de sódio para degradação do endocarpo de sementes de cafeeiro com diferentes graus de umidade. Revista Brasileira de Sementes, v.30, n.1, p.150-160, 2008. 